\section{Situación de la leptospirosis en el Urabá antioqueño colombiano: estudio seroepidemiológico y factores de riesgo en población general urbana}

\author{
Leptospirosis in Uraba, Antioquia, Colombia: \\ a seroepidemiological and risk factor \\ survey in the urban population
}

\footnotetext{
1 Instituto Colombiano de Medicina TropicalUniversidad CES, Medellín, Colombia.

Correspondencia P. Agudelo-Flórez Instituto Colombiano de Medicina TropicalUniversidad CES. Cra 43A No 52 Sur-99, Sabaneta-Colombia, AA 52162.

pagudelo@ces.edu.co
}

\begin{abstract}
Leptospirosis is a widespread zoonosis in tropical regions. The prevalence is unknown in the Colombian region of Uraba. A cross sectional study was conducted from March to October 2000 in order to determine the prevalence of Leptospira spp. antibodies and describe risk factors in nine counties in the region. The sample consisted of 582 individuals, who answered a questionnaire and had blood samples drawn to determine risk factors. Detection of Leptospira spp. antibodies was based on indirect inmunofluorescence and microagglutination. Seroprevalence was 12.5\% (95\% CI: 10.01-15.5). No differences were observed according to race, gender, occupation, age, living conditions, or time of residence in the area. L .interrogans serovar Grippotyphosa was the most prevalent species, identified in 53 individuals. Titers were $>1: 400$ in 38 seropositive individuals. In conclusion, there is a high prevalence of Leptospira spp. antibodies in the area, where it is thus necessary to establish control measures to decrease the risk of environmental exposure to leptospirosis.
\end{abstract}

Leptospirosis; Seroprevalence; Risk Factors
Piedad Agudelo-Flórez 1

Berta Nelly Restrepo-Jaramillo 1

Margarita Arboleda-Naranjo 1

\section{Introducción}

La leptospirosis es una zoonosis de gran incidencia en regiones tropicales, debido a factores ambientales, climáticos y sociales que favorecen la transmisión. En algunas zonas templadas y tropicales es considerada una enfermedad re-emergente. El agente etiológico corresponde a las especies patógenas del género Leptospira. Estas especies pueden infectar a la mayoría de especies de mamíferos, cuando éstos entran en contacto directo o indirecto con agua o suelo contaminado, con orina de hospederos adaptados y reservorios de la infección 1,2,3.

En los seres humanos la infección se presenta en forma esporádica o en brotes epidémicos. Cuando causa enfermedad se presenta como un síndrome febril agudo con manifestaciones clínicas variadas, por lo cual su diagnóstico definitivo, requiere tener en cuenta los antecedentes epidemiológicos, la presencia de anticuerpos y en algunos casos el aislamiento del microorganismo. El amplio espectro de síntomas clínicos hace que el diagnóstico médico sea difícil, con la consecuencia de que el curso de la enfermedad pueda variar rápidamente de formas intermedias a fatales $1,2,3,4$.

La mayoría de los casos se presentan en adultos jóvenes entre los 20 y 40 años, siendo más afectados los hombres que las mujeres, pero en las regiones donde hombres y mujeres trabajan en idénticas condiciones, la tendencia de la 
enfermedad es a igualarse en los dos sexos, hecho que comprueba la existencia de un factor ocupacional para la enfermedad ${ }^{3}$.

Los reservorios más comunes son las ratas, perros, bovinos, porcinos, equinos, zorrillos, cabras, conejos y murciélagos. Las ratas y los bovinos se han considerado como los reservorios más importantes, hecho que se explica porque el $\mathrm{pH}$ alcalino de la orina en estos animales favorece la supervivencia de Leptospira; como el hombre tiene una orina relativamente ácida para el germen, es considerado un mal reservorio, pero sí es un huésped susceptible a todas las serovariedades patógenas de Leptospira ${ }^{3}$.

La causa más frecuente de contagio para el hombre es el contacto indirecto con animales infectados, a través de aguas, suelos húmedos, vegetación o alimentos contaminados con la orina; otros animales pueden infectarse directamente con material post-aborto, placentas infectadas o por contacto sexual. La infección con la serovariedad Icterohaemorragiae es la más común en el hombre y se asocia con la exposición a perros infectados, aunque también es de alta prevalencia en los roedores 4,5,6.

Generalmente, se reconocen tres tipos de exposición para el hombre: una ocupacional, que afecta a trabajadores que están expuestos directamente al animal infectado o a sus residuos, siendo Hardjo (asociado a bovinos) y Pomona (asociado a porcinos) los serovares con los que más frecuentemente se está en contacto en esta categoría de riesgo. Otra es la exposición recreativa, que se presenta en personas que acampan, bañistas, excursionistas o exploradores y deportistas, así como la exposición causada por inundaciones y desastres naturales 1,2,6,7.

En Colombia existen pocos datos sobre prevalencia de la leptospirosis humana en población general, lo mismo que sobre factores de riesgo asociados con la enfermedad y formas de exposición. El primer registro de la enfermedad en Colombia es de finales de la década de los 60, donde se registra la enfermedad humana causada por el serovar Icterohaemorragiae con 4,28\% de humanos positivos ${ }^{8}$. El único brote epidémico documentado en el país se inicia en agosto de 1995 , en el departamento de Atlántico ${ }^{9}$, con un total de 47 casos confirmados y 284 casos sospechosos, con una letalidad del $17 \%$ entre los casos confirmados. Se aisló Leptospira de las serovariedades Icterohaemorragiae, Pomona y Canicola (Datos del Departamento Administrativo de Salud de Barranquilla, 1996).

Ochoa et al. 10 realizaron un estudio para determinar la prevalencia de leptospirosis en una región Antioqueña de producción lechera y encontraron que el $22,4 \%$ de los operarios tenían títulos para Leptospira, Orrego et al. 11 encontraron prevalencias desde $3,9 \%$ hasta $14,3 \%$ en trabajadores de explotaciones porcinas de Manizales, por su parte Nájera et al. 12 determinaron una prevalencia para leptospirosis del $11 \%$ en un grupo de trabajadores de carnicerías y arroceras en los departamentos de Córdoba y Sucre, y finalmente Ferro et al. 13 encontraron prevalencias de anticuerpos de 23,3\% en la ciudad de Cali.

Sebek et al. 14 realizaron para Colombia el mayor estudio seroepidemiológico en población humana general del que se encuentra registro. Examinaron serológicamente 353 personas entre jóvenes y adultos sanos en cinco localidades colombianas usando la prueba de microaglutinación (MAT), con 15 diferentes serogrupos, encontrando una positividad general de $18,4 \%$, principalmente por las serovariedades Icterohaemorragiae y Grippotyphosa.

Estos reportes demuestran la circulación de Leptospira spp. en Colombia, sin embargo, la situación real de la enfermedad es desconocida en la gran mayoría de las regiones del país. Aunque la prevalencia de leptospirosis en la región del Urabá antioqueño no se conoce, la zona puede considerarse de riesgo potencial por presentar, (1) zonas con urbanización deficiente, (2) concentración de roedores en áreas urbanas principalmente en barrios periféricos, en las áreas de invasión, en las áreas de residencia cercanas a las márgenes de ríos de la zona, como es el caso del río Apartadó, y en las áreas rurales de los municipios (3) zonas de riesgo para inundación y desbordamientos principalmente en los meses de mayo-junio y septiembre-noviembre cuando se incrementa el régimen de lluvias, (4) existencia de depresiones naturales o artificiales que se sabe que en épocas de lluvia son el medio de cultivo natural para Leptospira, lo que permite su permanencia en el ambiente, (5) falta de saneamiento ambiental que garantice un manejo adecuado de basuras y (6) falta de laboratorios de referencia en la zona que ofrezcan diagnóstico para leptospirosis.

Esta situación planteó la necesidad de estudiar la seroprevalencia de anticuerpos contra Leptospira spp. en habitantes de la zona urbana de la región de Urabá, para determinar el estado real de la infección y algunos de sus factores de riesgo, información necesaria, para orientar las intervenciones en salud y de control ambiental en la zona. 


\section{Metodología}

\section{Descripción del área de estudio}

La región del Urabá antioqueño está localizada al noroeste del departamento de Antioquia, Colombia, en el Golfo de Urabá y cuenta con 11 municipios, 9 de los cuales fueron incluidos en el estudio; los otros dos no se incluyeron por difícil acceso geográfico (Figura 1). La población de esta región representa el 7,6\% de toda la población de Antioquia (Departamento Administrativo Nacional de Estadística - DANE. Censo 1993, Resumen Nacional. Santafé de Bogotá; 1996). La actividad económica predominante es el cultivo y exportación del banano. La zona se ha caracterizado por migración constante de la población en busca de fuentes de trabajo, por la presencia de problemas de orden público y por la presentación de inundaciones en épocas de lluvias.

Figura 1

Localización geográfica de los municipios encuestados de la región del Urabá. Antioquia, Colombia.

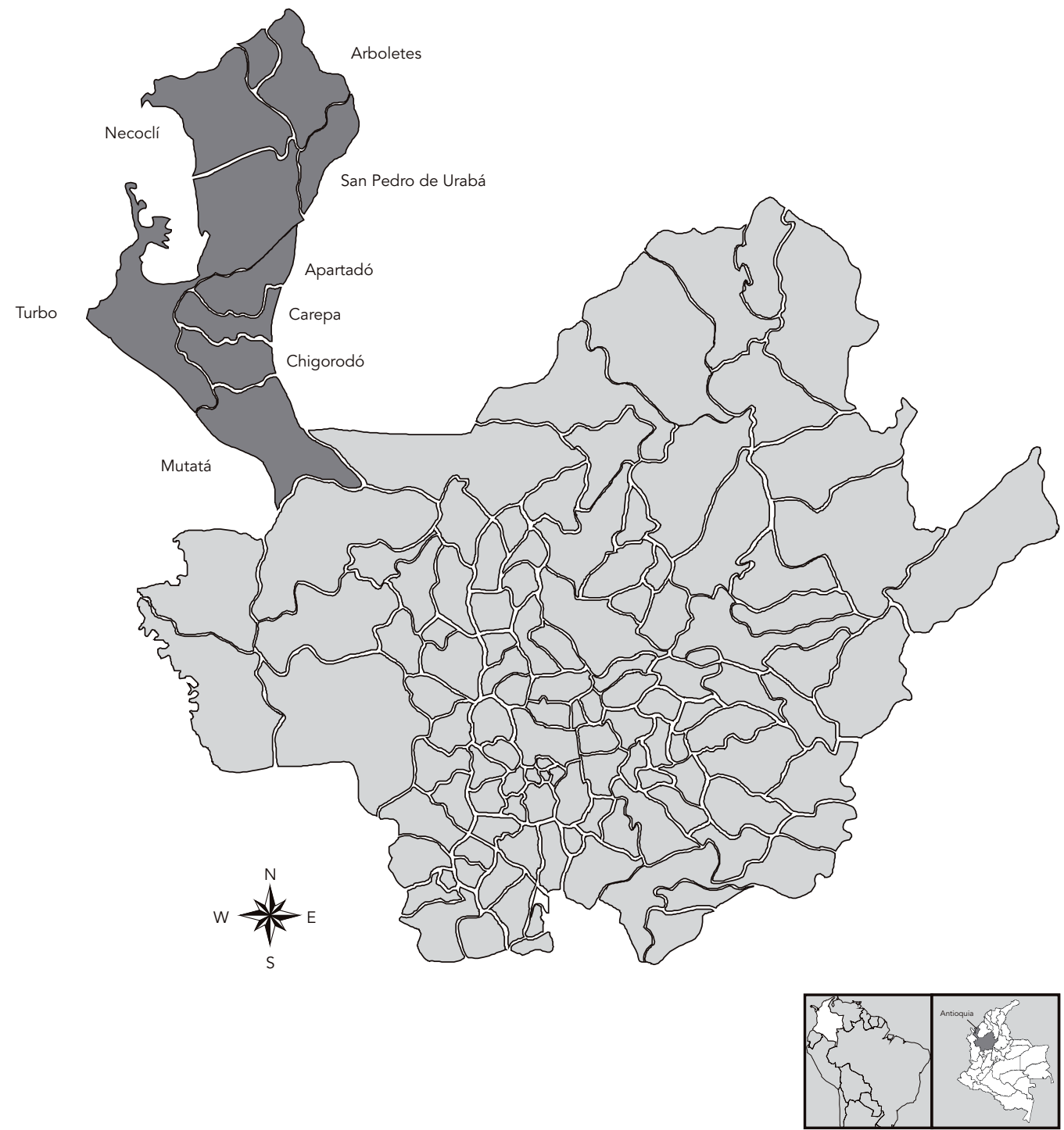




\section{Materiales y métodos}

Se realizó un estudio descriptivo de corte, entre marzo y octubre del año 2000. Este período fue escogido con el propósito de realizar el muestreo tanto en épocas de lluvia como de sequía en la zona. El total de personas a encuestar se calculó en Epi Info, versión 6 (Centres for Disease Control and Prevention, Atlanta, Estados Unidos), sobre la base de un universo de 153.405 habitantes de la zona urbana de los municipios de la región, según censo del DANE, con un error de muestreo del $4,1 \%$, un nivel de confianza del $95 \%$ y una prevalencia del evento del $50 \%$, para un total de 569 individuos a encuestar. La muestra se distribuyó de forma proporcional para cada municipio. La unidad de muestreo fue la vivienda y la unidad de análisis todos los miembros de una familia residentes en las viviendas seleccionadas. La información del marco muestral se obtuvo de los mapas de las cabeceras municipales suministrados por el DANE, actualizados con la información de las Oficinas de Planeación y del Sistema de Información de Beneficiarios (SISBEN) de los municipios. El muestreo fue aleatorio multietápico, estratificado y por conglomerados.

La información sociodemográfica y de factores de riesgo de la vivienda se obtuvo mediante la aplicación de un formulario. El procedimiento de la selección de la muestra fue realizado en cada municipio por los investigadores y la recolección de la información fue hecha por los investigadores y por auxiliares de campo entrenados para este fin. Se solicitó consentimiento informado y escrito a todos los participantes. En el caso de ser menor de 15 años el consentimiento era solicitado a un adulto responsable. El estudio fue avalado por el comité de ética del Instituto Colombiano de Medicina Tropical-Universidad CES (ICMT-CES).

En las viviendas seleccionadas, a todos los miembros de la familia se les tomó una muestra de sangre por venopunción, recolectando alrededor de $10 \mathrm{ml}$ de sangre en los adultos y $5 \mathrm{ml}$ en los niños menores de cinco años. Las muestras se centrifugaron y separaron en el laboratorio del hospital del respectivo municipio y posteriormente se enviaron al ICMT-CES sede de la ciudad de Medellín para la ejecución de las pruebas serológicas.

Para la determinación de la seroprevalencia se usó la detección de anticuerpos Inmunoglobulina G (IgG) contra Leptospira spp. con la prueba de Inmunofluorescencia Indirecta (IFI), esta prueba tiene sensibilidad del $87 \%$ y especificidad del $100 \%$, de acuerdo con la validación hecha para Colombia por Agudelo-Flórez et al. 15. El antígeno utilizado para esta técnica se obtuvo de un cultivo en medio líquido de 3 a 4 días de $L$. biflexa cepa Patoc 1, que es la recomendada por la Organización Mundial de la Salud (OMS) para su ejecución. Para esto se hicieron diluciones dobles de los sueros a evaluar usando solución salina de fosfatos (PBS pH 7,2), desde 1:10 hasta 1:2.560, y se colocaron en cada círculo con el antígeno fijado. En cada prueba se procesaron sueros control positivo y negativo para leptospirosis. Después de incubar en cámara húmeda a $37^{\circ} \mathrm{C}$ por media hora, las placas fueron lavadas en PBS tres veces, durante 10 minutos cada vez. Se colocó en cada círculo, conjugado anti-IgG marcado con fluoresceína (bioMérieux) previamente titulado. Después de incubar y de lavar en las condiciones señaladas anteriormente, se procedió al montaje de las placas con glicerol-PBS y se observó al microscopio de fluorescencia Nikon con un filtro de 495nm con aumento de 40X. Se determinó la positividad de las muestras comparándolas con los controles positivos y negativos y se definió el título positivo. El título del suero fue la más alta dilución que diera una lectura de fluorescencia, comparable a la del control positivo. Se consideró que una persona era seropositiva para Leptospira spp., si el resultado del estudio serológico para IgG tenía títulos iguales o superiores a 1:80.

A los sueros positivos por IFI se les realizó MAT, siguiendo las directrices de la OMS 16. Se utilizó un panel de seis serovariedades de Leptospira así: serovares Icterohaemorrhagiae, Pomona, Grippotyphosa, Canicola, Bratislava y Hardjo. Estas serovariedades corresponden a aquellas registradas como más prevalentes en población humana en Colombia ${ }^{14}$. Se consideraron positivos los títulos donde se encontraron aglutinaciones de al menos el 50\% de leptospiras con respecto al control. Títulos iguales o mayores a 1:100 fueron considerados positivos. Se consideró coaglutinación cuando la misma muestra presentaba aglutinaciones con dos o más serovariedades.

\section{Análisis estadístico}

El análisis estadístico fue realizado en Epi Info, versión 6 . A las variables cuantitativas se les calculó media y desviación estándar y a las variables cualitativas, medidas de frecuencia absoluta y relativa. La comparación entre los grupos se hizo mediante la prueba $\chi^{2}$, la fuerza de asociación utilizada fue el odds ratio (OR) con sus correspondientes intervalos de confianza del 95\% (IC95\%) y el valor de p. Se aceptó un nivel de significancia, $\mathrm{p}<0,05$. 


\section{Resultados}

Aspectos sociodemográficos

de las personas encuestadas

En total fueron estudiadas 582 personas. Se aumentaron 13 encuestados a la muestra calculada inicialmente (569), porque eran miembros de familias seleccionadas. La mayor participación la tuvieron los municipios de Apartadó (28,6\%), Turbo (29\%) y Chigorodó (18,4\%) que son los de mayor población. El 56,9\% correspondió a mujeres y el $43,1 \%$ a hombres. El promedio de edad de los participantes fue 21,7 años, con una desviación estándar de 17,4 años. La edad máxima fue 85 años y la mínima menos de 1 año. El 50\% de los participantes era mayor de 17 años y el $75 \%$ menor de 31 años. La edad más frecuente fue tres años. La mayoría de los encuestados nacieron en el departamento de Antioquia 76,2\%, seguido de Chocó, 9,1\% y Córdoba 8,6\%. El promedio de años de residencia en la zona fue 10,7 años, con un máximo de 74 y un mínimo de menos de un año. La mitad de los participantes llevaban siete años o menos residiendo en la zona. Este dato se obtuvo de 501 participantes.

Predominaron los encuestados de raza mestiza $(57,7 \%)$, seguida de la afroamericana $(39,9 \%)$. Los indígenas fueron el 2,4\% de los participantes. Los oficios más comunes fueron: estudiante $(32,1 \%)$ y ama de casa $(23,2 \%)$; seguido de "otros oficios no clasificados" (17,5\%) y agricultores $(5,7 \%)$. No tener un oficio habitual por ser niño, anciano o discapacitado representó el 18,9\%. El $2,2 \%$ de todos los encuestados estaban desempleados.

\section{Seroprevalencia de anticuerpos IgG contra Leptospira medidos por IFI}

El porcentaje de personas seropositivas para anticuerpos IgG contra Leptospira medidos por IFI fue de 12,5\% (73/582; (IC95\%: 10,01-15,5). Seis de los nueve municipios encuestados de la región registraron personas con presencia de anticuerpos contra Leptospira. Los municipios con mayor porcentaje fueron Carepa, Necoclí y San Pedro de Urabá (27,3\%, 25\% y 25\% respectivamente). Le siguen en frecuencia Apartadó 14,8\%, Turbo $11,8 \%$ y Chigorodó 7,5\%.

Seroprevalencia de anticuerpos IgG contra Leptospira medidos por IFI según características sociodemográficas

Todos los grupos de edad, a excepción del grupo de 50 a 54 años, presentaron personas con anticuerpos contra Leptospira. Los de mayor frecuencia fueron el de 35 a 39 años y el de 60 y más (ambas 21,7\%) Tabla 1. Aunque no se observó una tendencia definida con respecto a la edad, los mayores porcentajes se encontraron en la población en edad productiva (20 a 44 años). Para este análisis de tendencia se utilizó el grupo menor de cinco años como punto de referencia. $\mathrm{Al}$ comparar la frecuencia de personas con anticuerpos contra Leptospira entre el grupo menor de 15 años, 10,2\% (16/157), con el de 15 y más años, 13,4\% (57/425), las diferencias no fueron estadísticamente significativas (OR: 0,73; IC95\%: $0,39-1,36 ; \mathrm{p}=0,36$ ).

Se encontró que el 15,1\% de los hombres y el $10,6 \%$ de las mujeres fueron seropositivos. Esta diferencia no fue estadísticamente significativa (Tabla 1). Con relación a la raza se encontró mayor seroprevalencia en la raza mestiza $(13,1 \%)$, seguida de la raza afroamericana $(12,1 \%)$. Las diferencias no fueron estadísticamente significativas (Tabla 1).

En todos los oficios se observaron personas con anticuerpos contra Leptospira, los considerados "otros oficios no especificados" fueron los de mayor seroprevalencia, seguido de desempleados, ama de casa y agricultor. No hubo diferencias estadísticamente significativas entre las frecuencias de anticuerpos para Leptospira por oficios (Tabla 1). Se observó un promedio de años de residencia similar en ambos grupos: seropositivos 11,1 años y seronegativos 10,6 años $(\mathrm{p}=0,25)$.

En cuanto a factores de riesgo de la vivienda (Tabla 2), se encontró un porcentaje de seropositividad para Leptospira semejante en las personas que habitaban viviendas de construcción inadecuada (cerramiento parcial en paredes y techos) y con aquellas que habitaban viviendas de construcción adecuada (completamente cerradas en paredes y techos) $11 \% v s .14,7 \%$. Fue mayor la proporción de seropositivos en viviendas con suministro de agua por el municipio que con otro tipo de suministro como pozo, lluvia o tanque $(13,4 \%$ vs. $8,9 \%)$ y a las que el municipio les recolecta las basuras, frente a los que queman o botan la basura en terreno baldío (13,6\% vs. $9,6 \%)$. Estas diferencias no fueron estadísticamente significativas.

Por la prueba de MAT fueron estudiadas 70 muestras positivas por IFI. No se tuvo disponibilidad de muestra de tres seropositivos. De estas 70 muestras, 68 (97,1\%) fueron positivas para algún serovar y dos negativas. El serovar Grippotyphosa fue positivo en 53 casos, Icterohaemorrhagiae en 31 seropositivos, Pomona en 20, Hardjo en 15, Canicola en 11 y Bratislava fue positivo en 10. En 18 seropositivos se presentaron títulos para una sola serovariedad de Leptospira, de los cuales 13 
Factores de riesgo sociodemográficos y seropositividad para leptospirosis. Región del Urabá antioqueño, Colombia.

\begin{tabular}{|c|c|c|c|c|c|}
\hline \multirow[t]{2}{*}{ Factores de riesgo } & \multicolumn{2}{|c|}{ Seropositivos para anticuerpos IgG } & \multirow[t]{2}{*}{ OR } & \multirow[t]{2}{*}{ IC95\% } & \multirow[t]{2}{*}{$p$} \\
\hline & $\%$ & Positivos/Total & & & \\
\hline \multicolumn{6}{|l|}{ Edad (años) } \\
\hline $0-4$ & 11,8 & $9 / 76$ & & & \\
\hline $5-9$ & 6,4 & $6 / 94$ & 0,51 & $0,15-1,66$ & 0,32 \\
\hline $10-14$ & 8,6 & $7 / 81$ & 0,70 & $0,22-2,21$ & 0,69 \\
\hline $15-19$ & 11,3 & $9 / 80$ & 0,94 & $0,32-2,79$ & 0,89 \\
\hline $20-24$ & 16,3 & $7 / 43$ & 1,45 & $0,44-4,71$ & 0,68 \\
\hline $25-29$ & 16,7 & $8 / 48$ & 1,49 & $0,47-4,65$ & 0,62 \\
\hline $30-34$ & 17,5 & $7 / 40$ & 1,58 & $0,48-5,18$ & 0,57 \\
\hline $35-39$ & 21,7 & $5 / 23$ & 2,07 & $0,52-7,97$ & 0,37 \\
\hline $40-44$ & 20,7 & $6 / 29$ & 1,94 & $0,54-6,87$ & 0,34 \\
\hline $45-49$ & 14,3 & $3 / 21$ & 1,24 & $0,24-5,81$ & 0,71 \\
\hline $50-54$ & 0,0 & $0 / 11$ & 0,0 & - & 0,59 \\
\hline $55-59$ & 7,7 & $1 / 13$ & 0,62 & $0,03-5,98$ & 1,0 \\
\hline 60 y más & 21,7 & $5 / 23$ & 2,07 & $0,52-7,97$ & 0,30 \\
\hline \multicolumn{6}{|l|}{ Género } \\
\hline Masculino & 15,1 & $38 / 251$ & & & \\
\hline Femenino & 10,6 & $35 / 331$ & 1,51 & $0,90-2,54$ & 0,12 \\
\hline \multicolumn{6}{|l|}{ Raza } \\
\hline Mestiza & 13,1 & $44 / 336$ & & & \\
\hline Afroamericana & 12,1 & $28 / 232$ & 1,10 & $0,64-1,88$ & 0,81 \\
\hline Indígena & 7,1 & $1 / 14$ & 1,96 & $0,26-41,8$ & 1,00 \\
\hline \multicolumn{6}{|l|}{ Oficio } \\
\hline Otros oficios & 18,6 & 19/102 & & & \\
\hline Agricultor & 12,1 & $4 / 33$ & 1,66 & $0,48-6,32$ & 0,54 \\
\hline Ama de casa & 13,1 & $18 / 137$ & 1,51 & $0,71-3,13$ & 0,32 \\
\hline Estudiante & 10,7 & $20 / 187$ & 1,91 & $0,92-3,98$ & 0,08 \\
\hline No pertinente & 9,1 & $10 / 110$ & 2,29 & $0,95-5,63$ & 0,06 \\
\hline
\end{tabular}

Tabla 2

Factores de riesgo de la vivienda y seropositividad para leptospirosis. Región del Urabá antioqueño, Colombia.

\begin{tabular}{|c|c|c|c|c|c|}
\hline \multirow[t]{2}{*}{ Factores de riesgo } & \multicolumn{2}{|c|}{ Seropositivos para anticuerpos lgG } & \multirow[t]{2}{*}{ OR } & \multirow[t]{2}{*}{ IC95\% } & \multirow[t]{2}{*}{$\mathrm{p}$} \\
\hline & $\%$ & Positivos/Total & & & \\
\hline \multicolumn{6}{|l|}{ Tipo de vivienda } \\
\hline Inadecuada & 11,0 & $37 / 337$ & 0,72 & $0,43-1,20$ & 0,20 \\
\hline Adecuada & 14,7 & $36 / 245$ & & & \\
\hline \multicolumn{6}{|l|}{ Suministro de agua } \\
\hline Otro suministro & 8,9 & $10 / 112$ & & & \\
\hline Conexión municipal & 13,4 & $63 / 470$ & 0,63 & $0,29-1,33$ & 0,25 \\
\hline \multicolumn{6}{|l|}{ Recolección de basuras } \\
\hline Otra & 9,6 & $15 / 157$ & 0,67 & $0,35-1,26$ & 0,24 \\
\hline Municipal & 13,6 & $58 / 425$ & & & \\
\hline
\end{tabular}


correspondieron a Grippotyphosa, con títulos desde 1:100 hasta 1:800. La coaglutinación más frecuente fue la de los serovares Grippotyphosa e Icterohaemorragie, la cual se observó en 31 seropositivos. En 38 participantes se presentó positividad para cualquiera de las serovariedades probadas en títulos iguales o mayores a 1:400 y en 15 los títulos eran iguales o mayores a 1:800. El mayor título obtenido se presentó para el serovar Icterohaemorragie (1:1.600), asociado con aglutinación para el serovar Grippotyphosa (1:800).

\section{Discusión}

Este es el primer estudio seroepidemiológico de leptospirosis, realizado en la zona urbana de nueve municipios de la región del Urabá antioqueño, Colombia, donde se demuestra una prevalencia de anticuerpos IgG contra Leptospira de $12,5 \%$, siendo las serovariedades asociadas con roedores y caninos, L. interrogans Icterohaemorrhagiae y Grippotyphosa, las más frecuentes.

La seroprevalencia de leptospirosis observada en la región de Urabá es similar a los hallazgos de Sebek et al. 14 en Colombia y comparable con reportes recientes de otros países latinoamericanos, tanto en ambientes rurales como urbanos 17,18,19,20,21. A su vez, estos datos son similares con los encontrados por nuestro grupo en una comunidad indígena rural, donde la prevalencia de anticuerpos para Leptospira, determinada por ELISA fue de $18,1 \% 22$. Esto es importante, pues clásicamente la enfermedad se ha considerado de índole rural, pero en los últimos años, por diferentes estudios de prevalencia llevados a cabo en ambientes urbanos, como el que reportamos aquí, se perfila un cambio en la epidemiología de la enfermedad 20,21.

Se conoce que la prevalencia de leptospirosis es mayor en hombres que en mujeres y se relaciona con actividades género-específicas. En el presente estudio la seropositividad para leptospirosis fue similar en el grupo de hombres y el grupo de mujeres. Johnson et al. 20 encontraron índices semejantes de seropositividad en ambos sexos, explicables, como en el caso de este reporte, posiblemente por la similitud de las actividades realizadas por hombres y mujeres en la zona de estudio y porque el tipo de exposición por ellos encontrada fue el ambiental, tipo de exposición que también podría estar influenciando la presentación de leptospirosis en la zona de Urabá, aunque esto deberá ser explorado en futuros estudios.

En términos generales se asume que las condiciones ambientales y sociodemográficas determinan la frecuencia de leptospirosis en una po- blación dada, sin embargo en el presente estudio se observó que las condiciones de las viviendas no son determinantes del riesgo, al igual que los oficios y la edad, por lo tanto otros factores de tipo socio-ambiental podrían estar influenciando el comportamiento de la seroprevalencia en la población del área urbana, tales como inundaciones, cercanía de las viviendas a las márgenes de los ríos y quebradas, los cuales podrían favorecer la aparición de brotes esporádicos que afectarían a la población general, independiente de las condiciones de la vivienda, interrumpiéndose este ciclo de transmisión una vez pasada la inundación. La presencia de esta situación ambiental en forma cíclica puede traer consecuencias impredecibles a nivel epidemiológico en la zona.

Se sabe que los anticuerpos IgG anti-Leptospira detectados por la técnica de MAT permanecen detectables por aproximadamente 6 a 12 meses después de la exposición a la infección 23,24, e incluso pueden durar por años. La presencia de personas mayores de 15 años con niveles de anticuerpos IgG en la población estudiada sugiere que la circulación de Leptospira en la región de Urabá es activa y constante. Este hecho se corrobora aún más con los datos de seropositividad en las personas con mayor tiempo de residencia en la zona (11 años), la baja seropositividad registrada en los niños y el hecho de que la mayoría de los encuestados seropositivos procedían del departamento de Antioquia.

Si se tienen en cuenta que uno de los criterios para definir caso clínico de leptospirosis es tener un título por MAT mayor de 1:400 para alguna de las serovariedades de Leptospira 2, la presencia de títulos por MAT, obtenidos en esta investigación, iguales o mayores de 1:400 en el 54,3\% de los casos positivos y en el 21,4\% mayores a 1:800, plantea que la zona es de alta endemicidad para leptospirosis y además plantea la posibilidad de que la enfermedad se esté presentando en la zona de forma asintomática, tal como fue registrado en Nicaragua, donde se determinó que la presentación asintomática de leptospirosis es común en áreas endémicas 17, lo que enfatiza más la posibilidad de que en la zona la enfermedad está subregistrada y pudiéndose estar presentándose de forma asociada con otras enfermedades prevalentes en la zona como son dengue y malaria. En el caso donde se presentó un título mayor de 1:1.600 la posibilidad de que estuviéramos frente a un caso de infección activa también debe ser tenida en cuenta.

El riesgo de exposición en las ciudades es importante, debido a las condiciones precarias de vida y de higiene en los domicilios y en su ambiente circundante, que favorecen la presencia de roedores y de animales domésticos con bac- 
teriuria. El agua es esencial para la supervivencia de Leptospira, por lo tanto es de esperarse un aumento de su frecuencia en épocas de abundantes lluvias 25. Dado que las serovariedades más prevalentes en la zona fueron $L$. interrogans Grippotyphosa e Icterohaemorrhagiae asociadas con roedores y caninos, se debe monitorear en la región la presencia de aguas contaminadas con orina de estos animales junto con la presencia de basuras, para intentar reducir la exposición ambiental de la población. Es necesario también promover campañas de vacunación contra Leptospira en los caninos y regular la población de perros callejeros existentes en la zona.

Sería importante realizar en estudios posteriores, aislamientos de cepas de Leptospira, para conocer su patogenicidad, virulencia, fuentes de infección y otros factores de riesgo que permitan conocer el curso clínico de la infección, modalidades clínicas de presentación, alternativas terapéuticas e intervenciones comunitarias apropiadas. Es preciso disponer, por lo tanto, de un diagnóstico, tanto en laboratorios de la zona como en laboratorios de referencia cercanos, que garanticen la detección oportuna de la población afectada y que orienten al clínico, y así de este modo se puedan emprender a tiempo las medidas de manejo e intervención por parte de las autoridades de salud municipal, departamental y nacional.

Asimismo, por el aumento de áreas suburbanas, áreas de invasiones rurales y semirurales para la construcción de viviendas, se plantea la necesidad de estudiar leptospirosis en ambientes silvestres de la zona, pues estos nichos albergan cepas cuya virulencia, patogénesis, e importancia para la salud humana y animal se desconoce. Es necesario además, que las autoridades de salud pública de la región incluyan la leptospirosis en la lista de enfermedades endémicas en la zona, que viene a añadirse a las tradicionalmente conocidas dengue y malaria.

\section{Resumen}

Leptospirosis es una zoonosis de gran incidencia en regiones tropicales. Su prevalencia es desconocida en la región del Urabá colombiano. Entre marzo y octubre del año 2000 se realizó un estudio descriptivo de corte para determinar la seroprevalencia de anticuerpos contra Leptospira spp. y describir algunos factores de riesgo en nueve municipios del Urabá. La población incluida fue de 582 personas a las cuales se les tomó una muestra de sangre y se le aplicó una encuesta sobre factores de riesgo. La detección de anticuerpos contra Leptospira spp. fue realizada por inmunofluorescencia indirecta y por microaglutinación. La seroprevalencia general en la zona fue 12,5\% (IC95\%: 10,01-15,5). No hubo diferencias en cuanto al sexo, raza, oficio, edad, años de residencia en la zona y características de la vivienda. L. interrogans serovar Grippotyphosa fue la especie más prevalente, identificándose en 53 de los seropositivos. En 38 seropositivos los títulos detectados fueron iguales o mayores a 1:400. En conclusión, existe alta prevalencia de anticuerpos contra Leptospira spp. Es necesario orientar las medidas de control para disminuir el riesgo de exposición ambiental a leptospirosis por parte de los habitantes de la zona.

Leptospirosis; Seroprevalencia; Factores de Riesgo

\section{Colaboradores}

P. Agudelo-Flórez presentó la idea, elaboró la propuesta de investigación, procesó las muestras y escribió el artículo. B. N. Restrepo-Jaramillo, elaboró el diseño muestral, participó en la recolección y procesamiento de la información y en la escritura del artículo. M. ArboledaNaranjo, participó en la recolección de la información y en la revisión del artículo.

\section{Agradecimientos}

A los empleados de los hospitales locales de los nueve municipios estudiados. Al Instituto Colombiano de Medicina Tropical- Universidad CES y a la Dirección Seccional de Salud de Antioquia por el aporte financiero. 


\section{Referencias}

1. Vinetz JM. Leptospirosis. Curr Opin Infect Dis 2001; 14:527-38.

2. Bharti AR, Nally JE, Ricaldi JN, Matthias MA, Diaz MM, Lovett MA, et al. Leptospirosis: a zoonotic disease of global importance. Lancet Infect Dis 2003; 3:757-71.

3. Meites E, Jay MT, Deresinski S, Shieh WJ, Zaki SR, Tompkins L, et al. Reemerging leptospirosis, California. Emerg Infect Dis 2004; 10:406-12.

4. Organización Panamericana de la Salud. Definiciones de caso: dengue y leptospirosis. Boletín Epidemiológico 2000; 21. http://www.paho.org/ Spanish/SHA/be_v2n2-casos.htm (accedido el 05/ May/2005).

5. Tappero JW, Ashford DA, Perkins BA. Leptospira species (leptospirosis). In: Mandel GL, Bennett JE, Dolin R, editors. Principles and practice of infectious diseases. $5^{\text {th }}$ Ed. Philadelphia: Churchill Livingstone; 2000. p. 2495-501.

6. Faine S. Guide pour la lutte contre la Leptospirose. Geneva: Organización Mundial de la Salud; 1987. (Publicación Offset, 67).

7. Sejvar J, Bancroft E, Winthrop K, Bettinger J, Bajani $\mathrm{M}$, Bragg S, et al. Leptospirosis in eco-challenge athletes, Malaysian Borneo, 2000. Emerg Infect Dis 2003; 9:702-7.

8. Bravo C, Restrepo M. Leptospirosis en Antioquia: II. Leptospirosis en perros y cerdos. Antioq Méd 1970; 20:19-23

9. Epsein PR, Calix O, Blanco J. Climate and disease in Colombia. Lancet 1995; 346:1243-4.

10. Ochoa JE, Sánchez A, Ruiz I. Epidemiología de la leptospirosis en una zona andina de producción pecuaria. Rev Panam Salud Pública 2000; 7:32531.

11. Orrego A, Giraldo-de-León G, Rios B, Valencia PA. Leptospirosis en personas de riesgo de quince explotaciones porcinas y de la central de sacrificio de Manizales, Colombia. Arch Med Vet 2003; 3:1-10.

12. Nájera S, Alvis N, Babilonia D, Alvarez L, Máttar S. Occupational leptospirosis in a Colombian Caribbean area. Salud Pública Méx 2005; 47:240-4.

13. Ferro BE, Rodríguez AL, Pérez M, Travi BL. Seroprevalencia de infección con Leptospira en habitantes de barrios periféricos de Cali, Colombia. Biomédica (Bogotá) 2006; 26:250-7.

14. Sebek Z, Sixl W, Valova M, Marth E, Dock M, Reinthaler FF. Serological investigations for leptospirosis in humans in Columbia. Geogr Med Suppl 1989; 3:51-60.

15. Agudelo-Flórez P, Restrepo M, Lotero MA. Evaluación de la prueba de inmunofluorescencia indirecta para el diagnóstico de leptospirosis humana. Biomédica (Bogotá) 2006; (26):216-23.
16. World Health Organization/International Leptospirosis Society. Human leptospirosis: guidance for diagnosis, surveillance and control, 2003. http://www.med.monash.edu.au/microbiology/ staff/adler/ils.html (accedido el 05/Feb/2006).

17. Ashford DA, Kaiser RM, Spiegel RA, Perkins BA, Weyant RS, Bragg SL, et al. Asymptomatic infection and risk factors for leptospirosis in Nicaragua. Am J Trop Med Hyg 2000; 63:249-54.

18. Vado-Solis I, Cardenas-Marrufo MF, Jimenez-Delgadillo B, Alzina-Lopez A, Laviada-Molina $\mathrm{H}$, Suarez-Solis V, et al. Clinical-epidemiological study of leptospirosis in humans and reservoirs in Yucatan, Mexico. Rev Inst Med Trop São Paulo 2002; 44:33540.

19. Leal-Castellanos CB, Garcia-Suarez R, GonzalezFigueroa E, Fuentes-Allen JL, Escobedo-De La Penal J. Risk factors and the prevalence of leptospirosis infection in a rural community of Chiapas, Mexico. Epidemiol Infect 2003; 31:1149-56.

20. Johnson MA, Smith H, Joeph P, Gilman RH, Bautista CT, Campos KJ, et al Environmental exposure and leptospirosis, Peru. Emerg Infect Dis 2004; 10:1016-22.

21. Segura ER, Ganoza CA, Campos K, Ricaldi JN, Torres S, Silva H, et al. Clinical spectrum of pulmonary involvement in leptospirosis in a region of endemicity, with quantification of leptospiral burden. Clin Infect Dis 2005; 40:343-51.

22. Restrepo BN, Agudelo-Flórez P, Lotero MA. Leptospirosis en Colombia: estudio seroepidemiológico y factores de riesgo en la comunidad indígena Emberá-Katío. Biomédica (Bogotá) 2005; 25 Suppl $1: 150$.

23. Da Silva MV, Nakamura PM, Camargo ED, Batista L, Vaz AJ, Romero EC, et al. Immunodiagnosis of human leptospirosis by dot-ELISA for the detection of IgM, IgG, and IgA antibodies. Am J Trop Med Hyg 1997; 56:650-5.

24. Abdulkader RC, Daher EF, Camargo ED, Spinosa C, Da Silva MV. Leptospirosis severity may be associated with the intensity of humoral immune response. Rev Inst Med Trop São Paulo 2002; 44: 79-83.

25. Nardone A, Capek I, Baranton G, Campese C, Postic D, Vaillant V, et al. Risk factors for leptospirosis in Metropolitan France: results of a national case-control study, 1999-2000. Clin Infect Dis 2004; 39:751-3.

Recibido el 14/Feb/2006

Versión final presentada el 12/Feb/2007

Aprobado el 19/Mar/2007 